\title{
Shear velocity structure of the Northland Peninsula, New Zealand, inferred from ambient noise correlations
}

\author{
Y. Behr, ${ }^{1}$ J. Townend, ${ }^{1}$ S. Bannister, ${ }^{2}$ and M. K. Savage ${ }^{1}$ \\ Received 30 June 2009; revised 3 December 2009; accepted 18 December 2009; published 14 May 2010.
}

[1] Ambient noise correlation has been successfully applied in several cases to regions with dense seismic networks whose geometries are well suited to tomographic imaging. The utility of ambient noise correlation-based methods of seismic imaging where either network or noise field characteristics are less ideal has yet to be fully demonstrated. In this study, we focus on the Northland Peninsula of New Zealand using data from five seismographs deployed in a linear pattern parallel to the direction from which most of the ambient noise arrives. Shear wave velocity profiles computed from Rayleigh and Love wave dispersion curves using the Neighborhood Algorithm are in good agreement with the results of a previous active source refraction experiment and a teleseismic receiver function and surface wave analysis. In particular, we compute a path-averaged Moho depth of $\sim 28 \mathrm{~km}$ along a $\sim 250 \mathrm{~km}$ profile. The use of both Rayleigh and Love wave measurements enables us to estimate the degree of radial anisotropy in the crust, yielding values of $2-15 \%$. These results demonstrate that ambient noise correlation methods provide useful geophysical constraints on lithospheric structure even for nonoptimal network geometries and noise field characteristics.

Citation: Behr, Y., J. Townend, S. Bannister, and M. K. Savage (2010), Shear velocity structure of the Northland Peninsula, New Zealand, inferred from ambient noise correlations, J. Geophys. Res., 115, B05309, doi:10.1029/2009JB006737.

\section{Introduction}

[2] Under certain circumstances, cross-correlating long intervals of ambient seismic noise between two seismographs has been shown to yield an estimate of the general Green's function for the station pair, and its surface wave part, in particular [e.g., Weaver and Lobkis, 2001a, 2004, 2005, 2001b; Derode et al., 2003; Larose et al., 2006; Snieder, 2004]. Utilizing the dispersive character of surface waves to create tomographic images of the 2-D velocity distributions for different central frequencies is becoming an almost routine tool in seismology [Shapiro and Campillo, 2004; Yang et al., 2007; Lin et al., 2008] and 3-D analysis is now increasingly common [e.g., Yao et al., 2006; Liang and Langston, 2009; Nishida et al., 2008]. In theory, an isotropic distribution of noise sources around a station pair or a highly heterogeneous medium is required to reconstruct the full Green's function [Sánchez-Sesma and Campillo, 2006; Wapenaar, 2006; Larose et al., 2006; Tsai, 2009]. In practice, however, even if these conditions are not fulfilled, cross correlations of diffuse waves can yield a meaningful estimate of the medium's Green's function [Paul et al., 2005; Yang et al., 2007].

\footnotetext{
${ }^{1}$ School of Geography, Environment and Earth Sciences, Victoria University of Wellington, Wellington, New Zealand.

${ }^{2}$ GNS Science, Lower Hutt, New Zealand.

Copyright 2010 by the American Geophysical Union. 0148-0227/10/2009JB006737
}

[3] In a pilot study, Lin et al. [2007] demonstrated ambient noise correlation tomography to be feasible in New Zealand using 1 year of continuous vertical component data recorded at 42 permanent broadband stations. The 2-D group velocity maps resulting from that study, for periods between 8 and $23 \mathrm{~s}$, agree well with known geological features [cf. Mortimer, 2004]. Because of New Zealand's elongate geometry, however, observations at periods longer than $\sim 23 \mathrm{~s}$ are restricted to along-strike, approximately northeast-southwest oriented paths, making a countrywide 3-D inversion impracticable. Because of its oceanic isolation, long shoreline and consequent high wave heights [Laing, 2000; Pickrill and Mitchell, 1979; Gorman et al., 2003], New Zealand serves as an excellent target for investigating seismological imaging techniques using ambient noise sources [Brooks et al., 2009a, 2009b].

[4] Although 2-D velocity maps computed at different periods are instructive and serve as a useful means of verifying cross-correlation results, more practical benefit lies in the computation of 2-D velocity-depth models or fully 3-D volumes, and several studies have recently addressed this matter. For example, Brenguier et al. [2007] used Rayleigh wave group velocities measured from cross correlation to construct a 3-D model of the Piton de la Fournaise volcano on La Réunion island. Yao et al. [2008] inverted Rayleigh wave phase velocities for 3-D shear velocity structure beneath the Tibetan Plateau, and Moschetti et al. [2010] used Love and Rayleigh wave phase and group velocities to infer the 3-D anisotropic crustal and uppermost mantle shear velocity structures of the western United States. All 

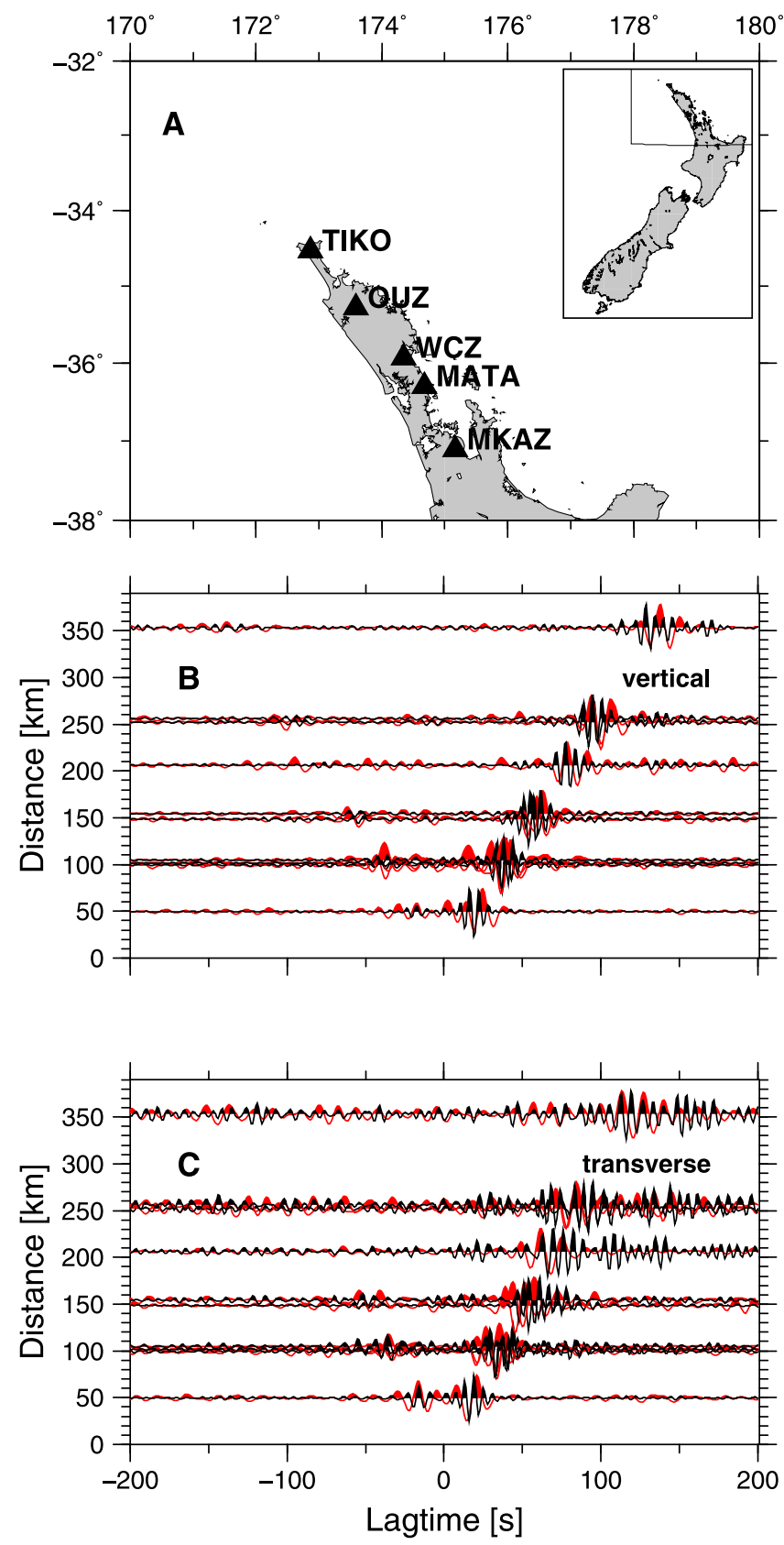

Figure 1. (a) Stations used in the Northland deployment (NORD). (b) Cross-correlation results in the 5-10 s period band (black) and 10-20 s period band (red) for the vertical component; strong asymmetries in amplitude imply dominant sources toward the northwest of the deployment. (c) Same as Figure 1b but for the transverse component.

three of these studies involved the construction of local dispersion curves at grid points spanning 2-D velocity maps for different periods. These dispersion curves were subsequently inverted for 1-D shear velocity profiles using Monte Carlo inversion methods to construct a final pseudo-3-D model.

[5] Here we examine the applicability of shear velocity profiling in an environment characterized by a high-ampli- tude, anisotropic noise field, using data recorded during short-term deployments on the Northland Peninsula, New Zealand. To do so, we compare 1-D shear velocity profiles obtained from noise cross correlation to the results of previous studies employing active sources and teleseismic events.

\subsection{Data}

[6] We use data recorded during the Northland Deployment (NORD) [Duclos, 2005] (see Figure 1) to test our processing and inversion procedures. The NORD deployment comprised five broadband stations (three Guralp-CMG 40T sensors, one Guralp-CMG 3ESP and one Streckeisen STS-2 sensor; Orion and Quanterra data loggers) located along a northeast-southwest line that were operated between September 2002 and February 2004 for durations varying from 11 to 16 months.

\subsection{Geology}

[7] Most of New Zealand's present-day continental crust is thought to have formed by terrane accretion in the late Cretaceous when it was part of Gondwana [Mortimer, 2004; Sutherland, 1999]. Rifting prior to the Late Cretaceous created the Northland Basin to the west of the Northland Peninsula followed by subsidence of the entire Northland region from the Late Oligocene until the Early Miocene. Between 25 and $22 \mathrm{Ma}$, sediments and oceanic crust were obducted and subsequently emplaced westward to form what is known as the Northland Allochthon, causing a rebound of the basement. At approximately the same time, a subduction zone developed off the east coast of Northland creating two volcanic chains, one along the east coast and the other along the west coast [Herzer, 1995; Spörli, 1989; Isaac et al., 1994].

[8] Northland's basement rock can be divided into three terranes [Mortimer, 2004]. The Murihiku Terrane in the west consists of sedimentary rocks and conglomerates that were deposited in fore-arc or back-arc basins. To the east of the Murihiku Terrane lies the Maitai Terrane, an ophiolite belt overlain by volcaniclastic sedimentary sequences that formed in a near-arc setting. The east coast of Northland is mainly part of the Bay of Islands Terrane, which comprises basalts, limestones, sandstones and mudstones formed in trench and trench slope environments. Large portions of these terranes are overlain by the Northland Allochthon.

[9] There are volcanological and geochemical indications of present-day mantle melting and partial melting in the crust in some parts of the Northland Peninsula [Hoke and Sutherland, 1999; Smith et al., 1993]. Occurrence of rhyolite outcrops and geothermal activity near the station at Omahuta (OUZ) have been suggested to be due to rhyolite intrusions in the crust [Heming, 1980]. High ${ }^{3} \mathrm{He} /{ }^{4} \mathrm{He}$ values and low upwelling rates indicate mantle melting beneath the Peninsula [Hoke and Sutherland, 1999; Huang et al., 1997].

\subsection{Previous Studies}

[10] Two principal seismological experiments have been conducted to determine crustal and upper mantle structure beneath the Northland Peninsula. Using wide-angle seismic refraction data, Stern et al. [1987] determined a $25 \pm 2 \mathrm{~km}$ average crustal thickness with $P$ wave velocities ranging between 5.3 and $5.9 \mathrm{~km} \mathrm{~s}^{-1}$ in the upper crust, $6.2 \mathrm{~km} \mathrm{~s}^{-1}$ in 
the lower crust and upper mantle velocities increasing from $7.6 \mathrm{~km} \mathrm{~s}^{-1}$ at the Moho to $7.9 \mathrm{~km} \mathrm{~s}^{-1}$ at $40 \mathrm{~km}$ depth. Horspool et al. [2006] jointly inverted teleseismic receiver functions and teleseismic surface wave phase velocity dispersion curves to derive shear velocity profiles. They inferred crustal thicknesses ranging from $26 \pm 1 \mathrm{~km}$ to $29 \pm$ $1 \mathrm{~km}$ and average shear velocities of 3.4 to $3.6 \mathrm{~km} \mathrm{~s}^{-1}$ in the upper crust, 3.6 to $4.0 \mathrm{~km} \mathrm{~s}^{-1}$ in the lower crust and $4.2 \pm$ $0.1 \mathrm{~km} \mathrm{~s}^{-1}$ in the upper mantle. Furthermore, they found manifestations of two low-velocity layers, one in the upper crust between stations Omahuta (OUZ) and Waipu Caves (WCZ) and the other in the upper mantle beneath Moumoukai (MKAZ).

[11] The NORD deployment's linear geometry is not ideal for ambient noise tomography, but the earlier studies conducted nearby make this region a useful testing environment for inverting surface wave dispersion curves from azimuthally anisotropic noise cross correlations to obtain shear velocity profiles. Moreover, the availability of threecomponent data enables us to examine differences in Rayleigh and Love wave propagation.

\section{Method}

\subsection{Preprocessing and Velocity Measurements}

[12] Our processing scheme is similar to that described by Bensen et al. [2007] and used previously in a New Zealand setting by Lin et al. [2007]. The instrument response for each station as well as the mean and the trend are first removed, the signals are decimated to $1 \mathrm{~Hz}$ sampling frequency if necessary and the traces are then cut to a uniform length of 1 day. Because of various operational factors, the number of resulting day-long traces for each of the five stations varies between 149 (MKAZ) and 535 (WCZ). The spectra for all three components for every available day and station pair are whitened and signals with large amplitudes in a typical earthquake period band of $15-50 \mathrm{~s}$ are downweighted. Cross correlation of all resulting traces for each day and subsequent stacking of the cross-correlation functions over the whole time span of the data set yields an estimate of the causal and anticausal portions of the Green's function between pairs of stations at positive and negative lag times, respectively. To compensate for amplitude differences between the causal and anticausal parts, a presumed consequence of heterogeneous noise source distributions, we add to each cross-correlation function its time-reversed trace to create what is known as the symmetric component cross correlation.

[13] Under the assumptions that Love and Rayleigh waves are polarized in the transverse and radial-vertical planes, respectively, and that they are dominated by fundamental modes, we measure Love and Rayleigh wave group and phase velocities using the multiple-filter technique (FTAN) of Levshin et al. [1992]. In phase velocity studies elsewhere the total number of cycles has generally been determined by comparing the FTAN output with a reference curve obtained from previous results [e.g., Lin et al., 2008]. We use the results of Horspool et al. [2006] as a reference curve for Rayleigh waves. As a suitable reference curve for Love waves does not exist for the Northland Peninsula we follow the suggestion of Lin et al. [2008] and use the Rayleigh wave reference curve with velocities increased by $9 \%$.

\subsection{Error Analysis}

[14] To assess the reliability of our measurements, we adapt the data selection and error analysis methods proposed by Bensen et al. [2007] and Lin et al. [2007] to account for the shorter recording times and nonideal network geometry. Dispersion curves are measured between periods of $5 \mathrm{~s}$ and a cutoff corresponding to twice the maximum wavelength $T_{\max }=\Delta /\left(2 * v_{\max }\right)$, where $\Delta$ is the station separation (in $\mathrm{km}$ ) and $v_{\max }$ is the assumed maximum surface wave velocity (in $\mathrm{km} / \mathrm{s}$ ), in order to avoid spurious signals from interference between the causal and anticausal parts [Shapiro et al., 2005; Lin et al., 2007].

[15] Signal-to-noise ratios are defined here as the ratio between the maximum amplitude of the symmetric component cross correlation within a predefined signal window and the root-mean-square of the trailing noise [e.g., Bensen et al., 2008; Yang et al., 2007]. We define the signal window as the part of the symmetric component cross correlation that lies within the expected minimal and maximal traveltimes of surface waves between a station pair and add a buffer of $500 \mathrm{~s}$ to the end of the window $\left(t_{\min }[\mathrm{s}]=\Delta / 4\left[\mathrm{~km} \mathrm{~s}^{-1}\right], t_{\max }[\mathrm{s}]=\right.$ $\left.500 s+\Delta / 1.5\left[\mathrm{~km} \mathrm{~s}^{-1}\right]\right)$. The signal after $t_{\max }$ is regarded as incoherent noise (Y. Yang, personal communication, 2009).

[16] As noise cross correlations are expected to be largely independent of the particular time at which the noise was recorded [see, e.g., Yao et al., 2006], we can stack daily cross correlations over different time periods and compute uncertainties from differences in the corresponding dispersion curves. We stack 100 days of cross correlations by shifting the stacking window in increments of 30 days, which results in up to 12 substacks.

\subsection{Inversion for $\mathbf{S}$ Velocity Profiles}

[17] Finding a velocity model that corresponds to an observed surface wave dispersion curve is a highly nonlinear optimization problem [e.g., Dunkin, 1965]. A common approach is to linearize the problem in the vicinity of a starting model and apply an iterative gradient method to find the best fitting model [e.g., Juliá et al., 2000]. This approach suffers, however, from several well-known problems [see, e.g., Parker, 1994]. First, the final model depends strongly on the starting model. Second, it is difficult to ascertain whether the final model corresponds to a local or a global minimum, and hence to quantify the solution's uncertainty. Third, gradient methods that guarantee convergence to a final model are known to be slow. The increased availability of computational power in recent years has made the use of direct search methods feasible, even when the parameter space is large.

[18] To overcome some of the problems associated with linearized approaches we have adopted the Neighborhood Algorithm (NA), a quasi-random direct search method similar to genetic algorithms or simulated annealing [Sambridge, 1999]. Sampling of the parameter space is steered by ranking randomly generated models according to a user-supplied criterion. Wathelet et al. [2004] successfully employed the NA in the inversion of surface wave dispersion curves for shallow shear velocity profiles (depth $<130 \mathrm{~m}$ ). Their results were consistent with data from active source experiments and a borehole $\log$ for the same site. Snoke and 


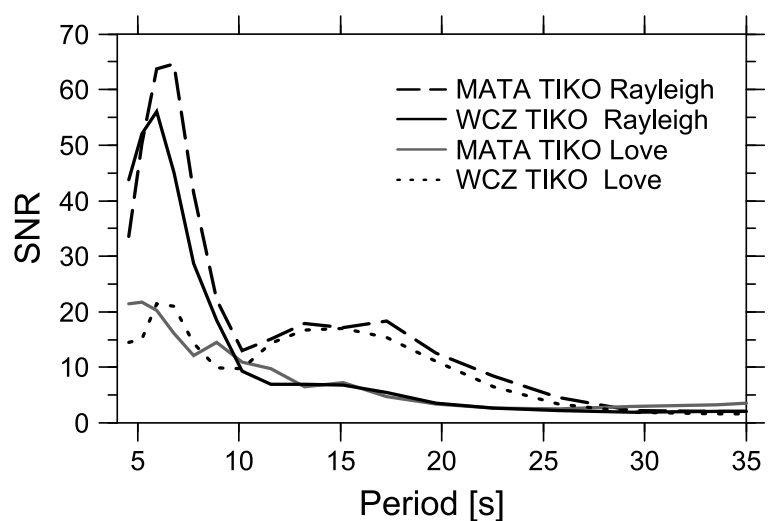

Figure 2. Signal-to-noise ratio (SNR) measurements for vertical (Rayleigh wave) and horizontal (Love wave) cross correlations between stations TIKO-MATA and TIKOWCZ (see Figure 1).

Sambridge [2002] compared the NA to an iterative gradient method for the inversion of surface wave dispersion curves in southeast Brazil and found that the best fitting models obtained with the two techniques agreed well. However, because the NA sampled larger portions of the parameter space, additional information was obtained about the ensemble of models that fully fit the data.

\section{Results}

[19] Of the 10 possible pairs of stations and corresponding travel paths, we focus on two between Tikorangi (TIKO) and Matakana (MATA) and TIKO and Waipu Caves (WCZ) to invert for shear velocity profiles using the NA. These two paths span the second and third greatest distances and have signal-to-noise ratios higher than those of other station pairs at comparable distances (Figure 2).

[20] Figures 3 and 4 show the velocity measurements for TIKO-MATA and TIKO-WCZ, respectively. As the two paths sample similar regions, we would anticipate obtaining similar dispersion curve measurements. However, the group velocities between the two station pairs differ substantially for Rayleigh waves (RG) at periods greater than $15 \mathrm{~s}$ and for Love waves (LG) over the whole period range considered. The Rayleigh wave phase (RP) and Love wave phase (LP) velocity measurements, in contrast, are very similar for both station pairs and to the reference curves taken from Horspool et al. [2006]. To ensure consistency of our phase and group velocity measurements, we checked that measured group velocity dispersion curves and the group velocity dispersion curves from phase velocity measurements were identical (i.e., $V_{g}=\partial \omega / \partial k$ ). A possible explanation for the discrepancy in group velocities is given by Tsai [2009], who showed that a strong noise source anisotropy off the interstation path can reduce the group velocity considerably while leaving the phase velocity almost unchanged. The fact that such a source only affects the group velocities between TIKO and WCZ could indicate a disturbing source close to station WCZ. Differences in signal-to-noise ratios for Love and Rayleigh waves for the secondary microseismic band (5-10 s) suggest different source mechanisms, as proposed by Longuet-Higgins

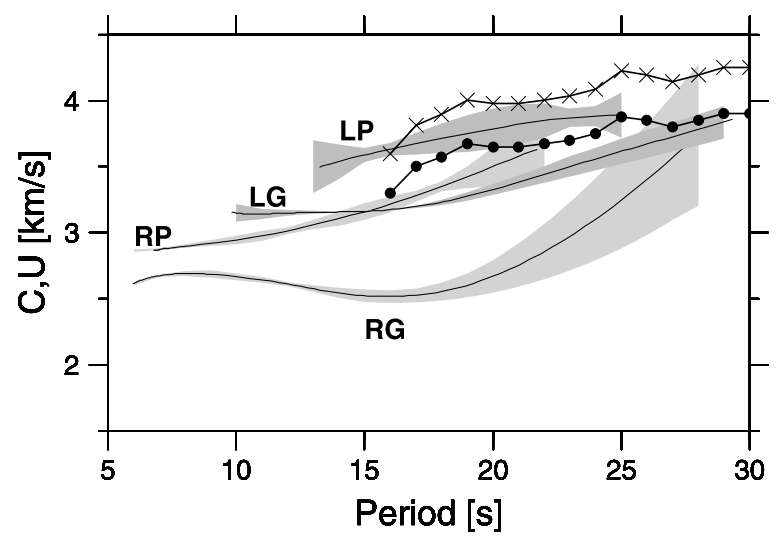

Figure 3. Rayleigh wave group velocity (RG), Rayleigh wave phase velocity (RP), Love wave group velocity (LG), and Love wave phase velocity (LP) dispersion curve measurements for cross correlations between TIKO and MATA (solid lines). Gray shaded areas mark one standard deviation for each measurement point. The line marked by circles corresponds to the reference curve from Horspool et al. [2006] used for the Rayleigh phase velocity measurements. The line marked with crosses corresponds to the reference curve for Love wave phase velocity measurements.

[1950]. While Love waves in the primary microseism band (10-20 s) are excited by direct coupling of ocean waves to the ocean bottom, they are mainly a result of scattering of Rayleigh waves in the secondary microseism band. Therefore the higher signal-to-noise ratios for TIKOWCZ compared to TIKO-MATA in the primary microseism band (Figure 2) support the suggestion of a localized source close to station WCZ.

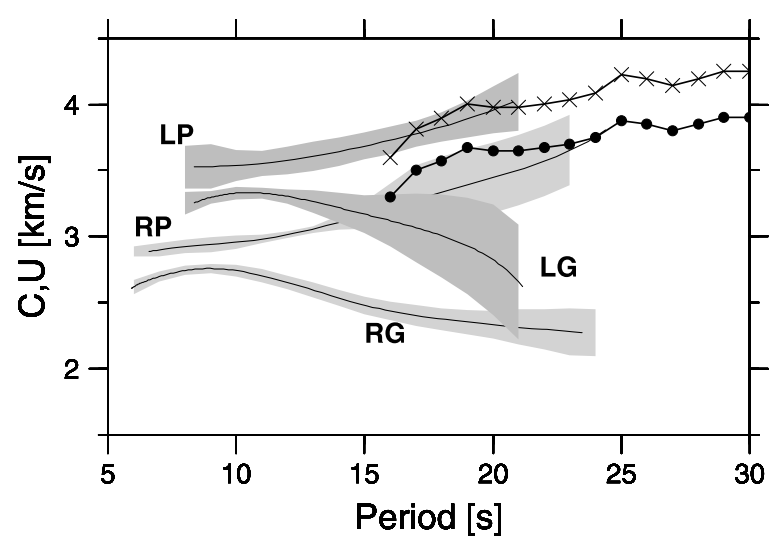

Figure 4. Rayleigh wave group velocity (RG), Rayleigh wave phase velocity (RP), Love wave group velocity (LG) and Love wave phase velocity (LP) dispersion curve measurements for cross correlations between TIKO and WCZ (solid lines). Gray shaded areas mark one standard deviation for each measurement point. The line marked by circles corresponds to the reference curve from Horspool et al. [2006] used for the Rayleigh phase velocity measurements. The line marked with crosses corresponds to the reference curve for Love wave phase velocity measurements. 
[21] We parameterize the model space using four layers over a half-space, three for the crust and one for the upper mantle. The $\mathrm{S}$ and $\mathrm{P}$ velocities, layer thickness and Poisson's ratios of each layer are allowed to vary substantially while the density is fixed. The misfit is a least squares misfit defined as $\sqrt{\sum_{i=1}^{n_{F}}\left(x_{\text {data }}-x_{\text {calc }}\right)^{2} /\left(x_{\text {data }}^{2} * n_{F}\right)}$, where $x_{\text {data }}$ is the velocity measurement, $x_{\text {calc }}$ the corresponding calculated value and $n_{F}$ is the total number of measurement points on a dispersion curve [Wathelet, 2005]. The grey shaded areas in Figures 5 and 6 illustrate the ranges in the shear velocitydepth plane that are sampled by the NA. The color depicts the fraction of the models with a misfit smaller than 0.1 that intersect a certain cell in the velocity-depth plane. The redder the color, the more velocity profiles cross that portion of the velocity-depth plane. The black line indicates the weighted average of the models plotted in color and the white line marks the average model derived by Horspool et al. [2006].

[22] Inversion results for Rayleigh wave phase and group velocities between TIKO and MATA (Figures $5 \mathrm{a}, 5 \mathrm{~b}$, and $5 \mathrm{~d}$ ) show three prominent velocity jumps, one at around $10 \mathrm{~km}$ depth, a small one around $20 \mathrm{~km}$ depth and the Moho at around $28 \mathrm{~km}$ depth. Figures $5 \mathrm{a}-5 \mathrm{c}$ show the synthetic dispersion curves for 100 models randomly drawn from all models with a misfit smaller than 0.1 . They are tightly distributed around the measurements (black dots). In contrast, the synthetic dispersion curves for the Rayleigh wave phase velocity between TIKO and WCZ are more spread out, reflecting the broad range of models with misfits smaller than 0.1 that we see in Figure 5e. For the reasons discussed above, we have not included the group velocity measurements between TIKO and WCZ in the inversion, which results in decreased resolution in this case relative to TIKO-MATA. However, the average velocity-depth profiles (black lines) agree well for the two different station pairs down to a depth of about $22 \mathrm{~km}$, below which the dispersion curve for TIKO-WCZ loses sensitivity due to its truncation at $23 \mathrm{~s}$ period. In this context it should be mentioned that by inverting for 1-D profiles, we encounter a tradeoff between the maximum depth that can be imaged and horizontal resolution along an interstation path. In other words, the longer the interstation path lengths, the less accurate any 1-D representation of a 3-D medium. Moreover shorter interstation distances result in shorter usable period ranges and correspondingly reduced depth resolution.

[23] The histogram of the Moho depth (i.e., the sum of crustal layer thicknesses) for the Rayleigh wave inversion between TIKO and MATA (Figure 7, dashed line) yields a mean Moho depth of $28.3 \mathrm{~km}$ and a standard deviation of $2.2 \mathrm{~km}$. This value corresponds within error margins to the depth of $25 \pm 2 \mathrm{~km}$ determined by Stern et al. [1987] from analysis of active source seismic refraction data and to the $26 \pm 1 \mathrm{~km}$ to $29 \pm 1 \mathrm{~km}$ inferred by Horspool et al. [2006] from the joint inversion of teleseismic surface waves and receiver functions. The shear velocity profiles calculated by Horspool et al. [2006] averaged for OUZ, WCZ and MATA (white line in Figures 5d and 5e) show slightly higher velocities in the crust than obtained from the noise correlation but generally correspond well to the average model for depths greater than $\sim 4 \mathrm{~km}$. Our dispersion curves are computed for periods longer than 5 and $10 \mathrm{~s}$, as opposed to 15 and $20 \mathrm{~s}$ in Horspool et al.'s [2006] study, so our results are expected to better constrain the velocity structure at such shallow depths.

[24] Compared to the Rayleigh wave inversion results (Figure 6a, 6c, and 6e), inversion of Love wave phase and group velocities between TIKO and MATA (Figures 6b, 6d, and 6f) reveals slightly higher velocities in the upper and middle crust and a Moho with a mean depth approximately $2 \mathrm{~km}$ shallower than observed with the Rayleigh wave data (Figure 7, solid line). One explanation for this discrepancy in Moho depths is a tradeoff between the thickness of the upper mantle layer and velocity in the lower crust layer. In other words, a velocity-depth model with a greater Moho depth requires higher velocities in the lower crust to fit the Love wave dispersion curves. With Love waves being sensitive mainly to horizontally polarized shear waves, this discrepancy would be a possible indication of radial anisotropy in the lower crust. To test this hypothesis, we invert both Rayleigh and Love wave phase and group velocities between TIKO and MATA with the upper crust thickness fixed to $9 \mathrm{~km}$ and the Moho depth fixed at $27 \mathrm{~km}$. The results (Figure 8) show that both Love and Rayleigh waves can be fitted well for a common structural model by allowing considerably higher velocities for Love waves than for Rayleigh waves in the lower crust. We estimate the distribution of radial anisotropy by randomly drawing 1000 values from the $\mathrm{S}$ velocity distribution for each layer and computing the radial anisotropy, which we here represent in terms of the magnitude of anisotropy $k=\left(V_{\max }\right.$ $\left.V_{\min }\right) / \bar{V}=2\left(V_{\mathrm{SH}}-V_{\mathrm{SV}}\right) /\left(V_{\mathrm{SH}}+V_{\mathrm{SV}}\right)$ [e.g., Stein and Wysession, 2003, section 3.6.2]. For the upper and lower crustal layer we obtain values of $2 \pm 0.6 \%$ and $15 \pm 0.5 \%$, respectively. The uppermost mantle shows negative anisotropy of $-6 \pm 0.5 \%$. However, as the dispersion curves have little sensitivity to velocities at depths deeper than $\sim 30 \mathrm{~km}$, this deepest value may represent an artifact (Figure 9).

\section{Discussion and Conclusion}

[25] The results obtained by shear velocity modeling of Rayleigh and Love wave dispersion curves derived from ambient noise correlation are in good agreement with those of previous studies using more traditional seismological techniques [Horspool et al., 2006; Stern et al., 1987]. This demonstrates that ambient noise correlation yields useful measurements even when the distributions of noise sources and seismographs are both highly asymmetric. Larose et al. [2006] demonstrated using 2-D numerical simulations that when the noise source distribution is asymmetric, a heterogeneous medium ( $\sim 1.5$ scatterers per unit area) is required to enable reconstruction of the complete Green's function. If that condition is not met, Larose et al.'s [2006] analysis suggests that only those interstation paths lying parallel to the predominant source back azimuth contribute to an estimate of the causal part of the Green's function in the cross-correlation process. The NORD deployment's linear geometry means that the interstation paths are near parallel and oriented northwest-southeast. Sinclair [2002] observed the highest density of tropical cyclones in the southwest Pacific from 1970 until 1997 to the northwest of New Zealand. In other words, the interstation paths considered 

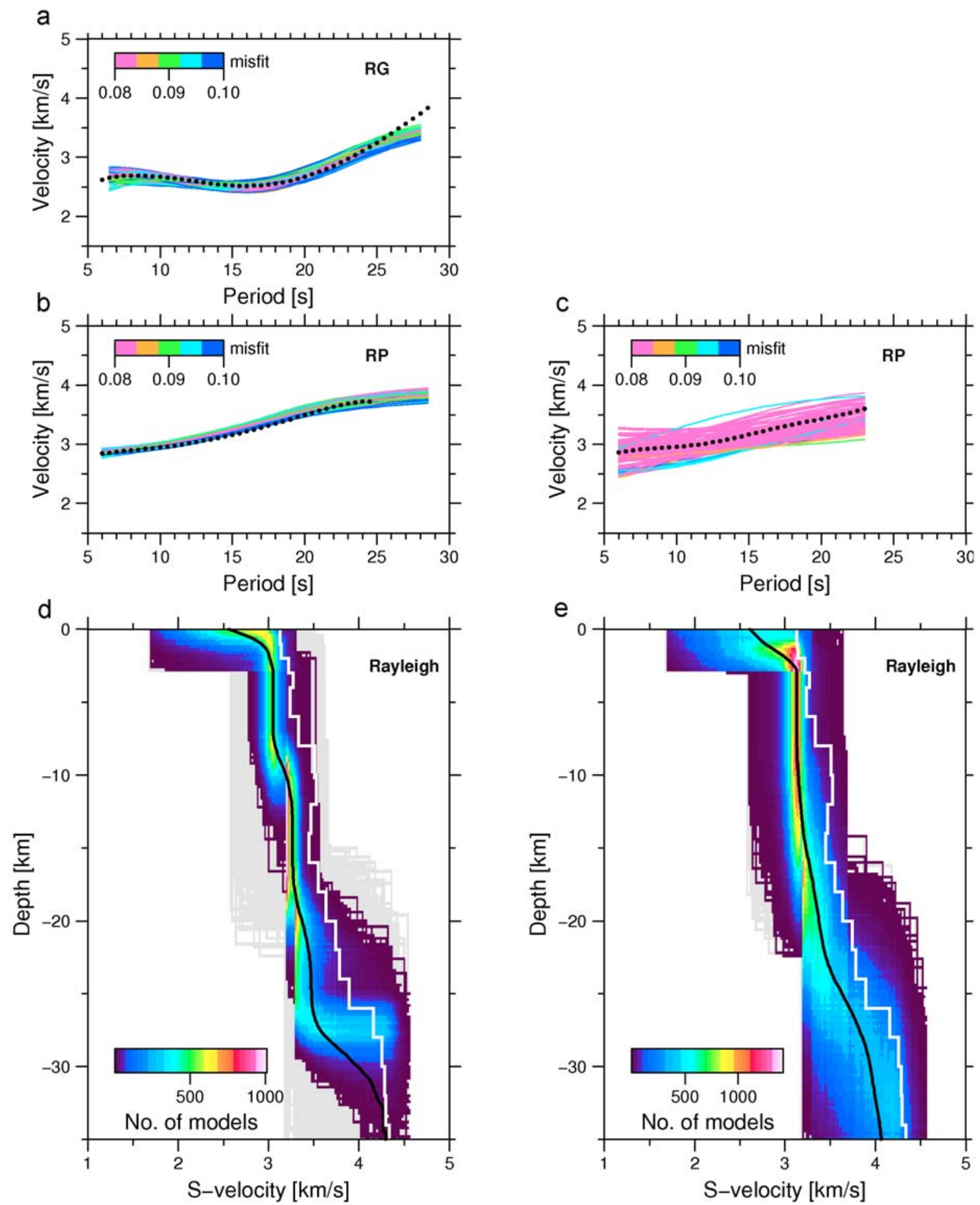

Figure 5. Inversion results for (d) Rayleigh wave group and phase velocity dispersion curves measured between Tikorangi (TIKO) and Matakana (MATA) and (e) Rayleigh wave phase velocity dispersion curves between Tikorangi and Waipu Caves (WCZ). The gray areas show the ensemble of all 10,050 models evaluated, and the colors illustrate the density distributions of models with misfits smaller than 0.1 . The thick black line in each case represents the weighted average of the models plotted in color. The white line shows the average model for the results of Horspool et al. [2006]. (a-c) The measured Rayleigh group (RG, Figure 5a) and Rayleigh phase (RP, Figures 5b and 5c) dispersion curves (black dots) on top of 100 synthetic dispersion curves that were drawn randomly from the corresponding ensemble of models with misfits smaller than 0.1 . 
a

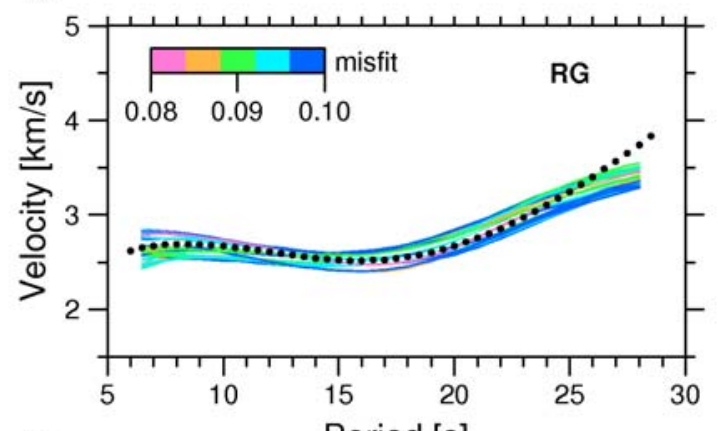

C

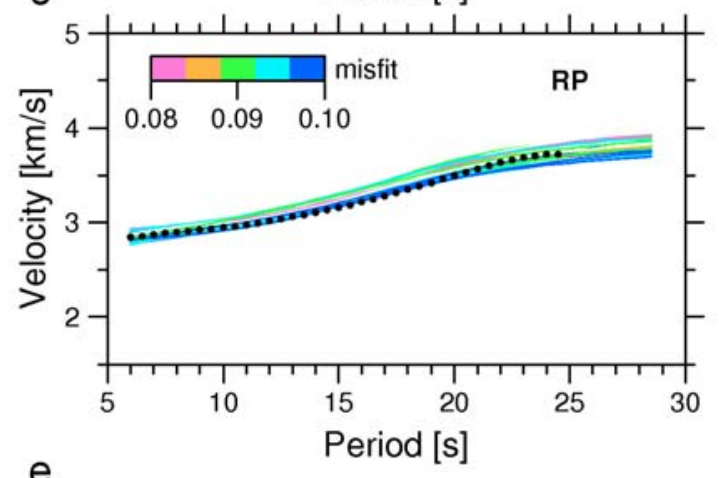

e

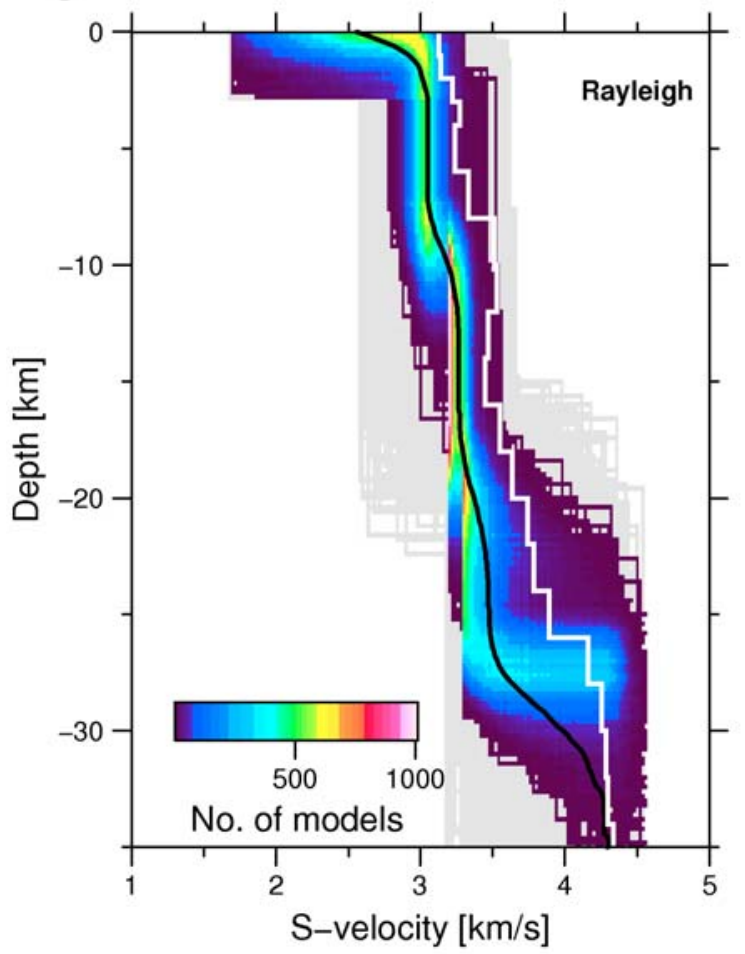

b

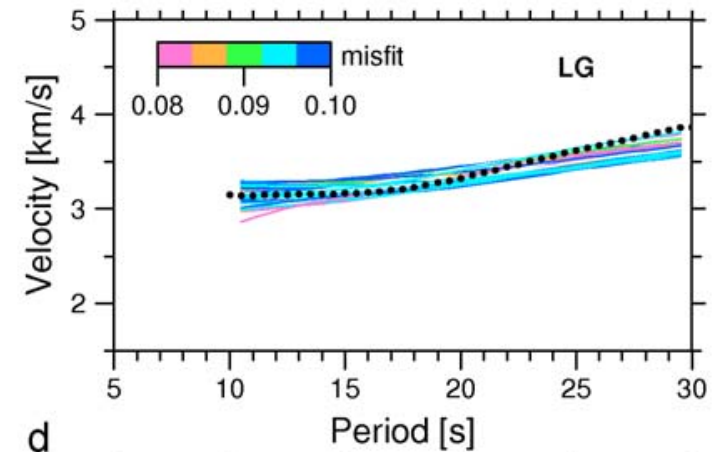

d

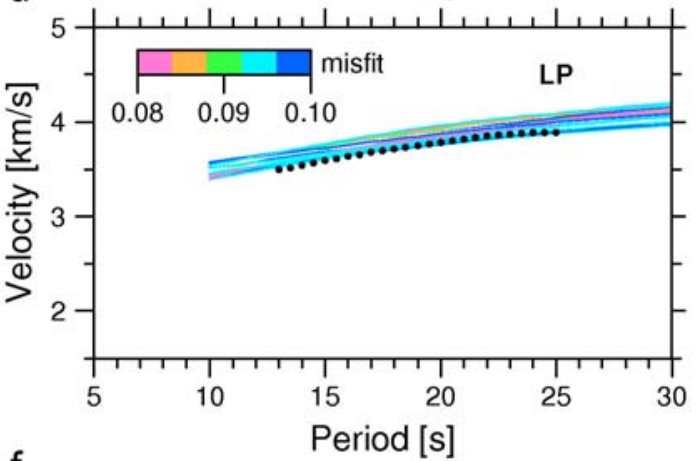

$f$

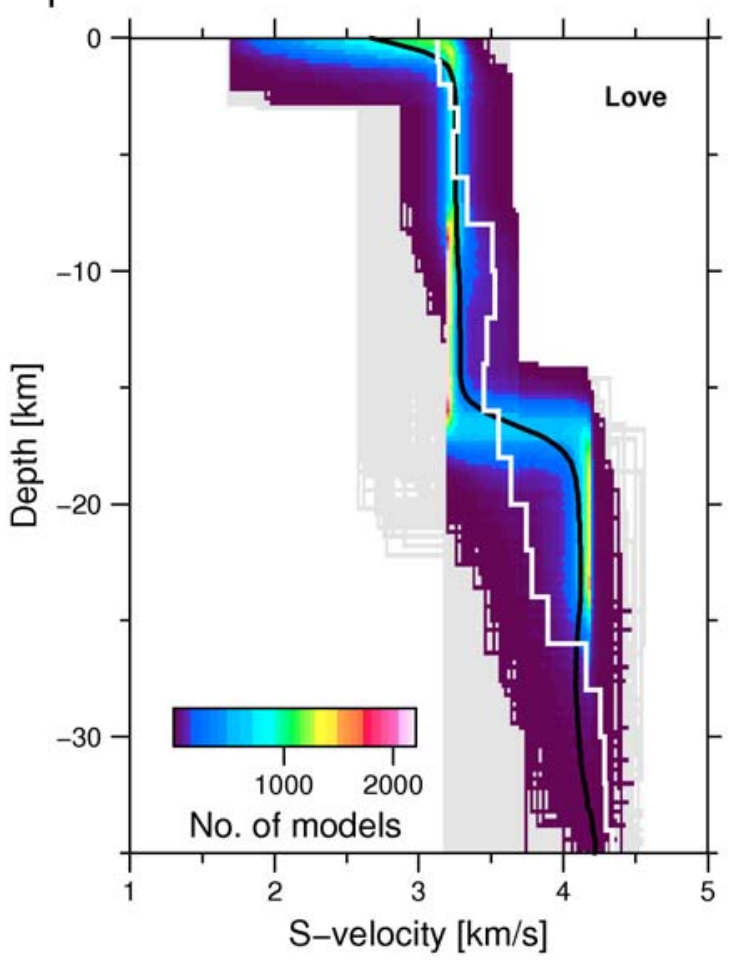

Figure 6. Inversion results for (e) Rayleigh and (f) Love wave group and phase velocity dispersion curves measured between Tikorangi and Matakana. The gray areas show the ensemble of all 10,050 models evaluated, and the colors illustrate the density distributions of models with misfits smaller than 0.1 . The thick black line in each case represents the weighted average of the models plotted in color. The white line shows the average model for the results of Horspool et al. [2006]. (a-d) The measured Rayleigh group (RG, Figure 6a) and Rayleigh phase (RP, Figure 6c) dispersion curves (black dots) and Love group (LG, Figure 6b) and Love phase (LP, Figure 6d) dispersion curves (black circles) on top of 100 synthetic dispersion curves that were drawn randomly from the corresponding ensemble of models with misfit smaller than 0.1 . 


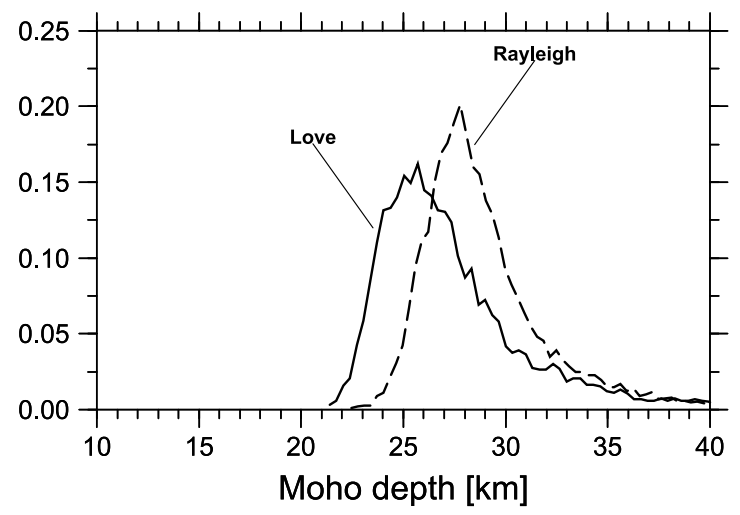

Figure 7. Normalized histograms of the Moho depth for the ensembles shown in Figure 6 in gray. The solid line indicates the histogram for the joint inversion of Love wave phase and group velocity measurements (Figures $6 \mathrm{~b}, 6 \mathrm{~d}$, and $6 \mathrm{f}$ ); the dashed line represents the histogram for the joint inversion of Rayleigh wave phase and group velocity (Figure 6a, 6c, and 6e).

here are subparallel to the direction in which most noise is generated. This is in agreement with noise source back azimuths estimated by Lin et al. [2007, Figure 15] from differences in signal-to-noise ratios between the causal and anticausal part of the cross correlations. The results of beam-forming measurements using a 61-element array in the western North Island [Brooks et al., 2009a, 2009b] also show the northwest of the North Island as one of the dominant ambient noise sources in New Zealand.

[26] Our analysis suggests that radial shear velocity anisotropy is required to account for differences in the Rayleigh and Love group and phase velocity dispersion curves, which depend on vertically and horizontally polarized shear velocities, respectively (for a recent discussion, see Endrun et al. [2008]). We estimate the magnitude of such radial anisotropy for the TIKO-MATA path to be $\sim 2 \%$ in the upper crust and $\sim 15 \%$ in the lower crust.

[27] Aside from near-radial anisotropy of 4-6\% inferred from receiver function analysis in the southern North Island and interpreted to be caused by schists derived from subducting sediments above the Pacific plate [Savage et al., 2007], we are not aware of other estimates of radial anisotropy in the upper or lower crust in greater New Zealand although azimuthal variations in anisotropy have been extensively studied [e.g., Marson-Pidgeon et al., 1999; Gerst and Savage, 2004; Audoine et al., 2004; Balfour et al., 2005; Duclos, 2005]. Using Love and Rayleigh waves from teleseismic events, Endrun et al. [2008] inferred radial anisotropy values for the lower crust in the Aegean region of between 4.0 and $7.7 \%$, with a maximum of $15 \%$. Shapiro et al. [2004] used surface wave dispersion measurements from teleseismic earthquakes to study crustal radial anisotropy in Tibet and related this to crustal thinning and middle to lower crustal flow. They observed values of around $8 \%$ in the lower crust. Azimuthal anisotropy as well as multipathing may contribute to traveltime differences between Love and Rayleigh waves [e.g., Endrun et al. 2008]. Yao and van der Hilst [2009] inferred a maximum phase velocity bias of 3\% from simulations of a heterogenous noise source distribution surrounding a homogeneous medium, which would correspond to variations of $\sim 0.1 \mathrm{~km} \mathrm{~s}^{-1}$ in our phase velocity measurements. Variations in $\mathrm{P}$ velocity can also affect the Rayleigh wave dispersion curves but not the Love wave dispersion curves, and thereby influence the estimated magnitude of radial anisotropy. Wathelet [2005] showed in sensitivity tests for a two-layer model that for Poisson's ratios of larger than $\sim 0.27$, the influence of the $\mathrm{P}$ velocity on Rayleigh wave dispersion curves is negligible. While the a priori values of 0.26 in the crust and 0.28 in the mantle assumed by Horspool et al. [2006] lie within a range that might still affect the dispersion curves, our observed values of $\sim 0.31$ in the crust and $\sim 0.35$ in the upper mantle are unlikely to influence the $\mathrm{S}$ velocity profiles inferred from Rayleigh wave dispersion curves. These points should be taken into account in future studies of radial anisotropy in New Zealand and elsewhere.

[28] The $\sim 28 \mathrm{~km}$ crustal thickness inferred here for the Northland Peninsula is similar to values observed throughout the western North Island of New Zealand [Horspool et al., 2006; Stern et al., 1987; Stratford and Stern, 2006]. Such values are approximately $10 \mathrm{~km}$ less than the global average thickness of continental crust [e.g., Fowler, 2005] and 7-12 km less than observed in the southern North Island [Savage, 1998; Holt and Stern, 1994].

[29] Stern et al. [1987] demonstrated that a $25 \mathrm{~km}$ thick crust would require a hotter than normal mantle lid to generate sufficient buoyancy to lift the Northland Peninsula above sea level. Limited crustal heat flow measurements suggest that the crust is somewhat hotter than normal in Northland (74 $\pm 4 \mathrm{~mW} \mathrm{~m}^{-2}$ [Pandey, 1981]), although heat flow studies conducted elsewhere in New Zealand suggest that those measurements are biased toward higher values by $10-15 \mathrm{~mW} \mathrm{~m}^{-2}$ due to assumptions about thermal conductivity [Funnell et al., 1996; Townend, 1999; Goutorbe et al., 2008]. As noted above, $P$ velocities in the uppermost mantle beneath Northland are relatively low (i.e., $7.6 \mathrm{~km} \mathrm{~s}^{-1}$ at $25 \mathrm{~km}$ [Stern et al., 1987]), and similarly low values are seen farther south in the western North Island in active source [Stratford and Stern, 2006] and mantle refraction (Pn) studies [Seward et al., 2009].

[30] Stern et al. [2006] recently hypothesized that the crust beneath the western North Island, including the Northland Peninsula, has been thinned by the convective removal of part of the lower crust and lithospheric mantle in response to a Rayleigh-Taylor instability. According to this model, upper plate lithosphere is thickened during subduction to such an extent that the thickened mantle root and lower crust become gravitationally unstable and detach from the upper crust, thereby thinning the crust and allowing hot asthenospheric material to upwell beneath it. As noted in the introduction, Northland is thought to have been part of a subduction zone at approximately $25 \mathrm{Ma}$. If the RayleighTaylor model is appropriate for this region, then future heat flow measurements may substantiate the seismological evidence for hot mantle material at depths of $\sim 25 \mathrm{~km}$.

[31] In conclusion, we have demonstrated the suitability of ambient noise correlation measurements for shear wave velocity modeling for a nonoptimal network configuration (namely, a linear array of five stations operated for up to 14 months) and highly directional noise-source distributions. The 1-D shear velocity models computed from surface wave dispersion curves obtained from vertical component ambient 


\section{a}
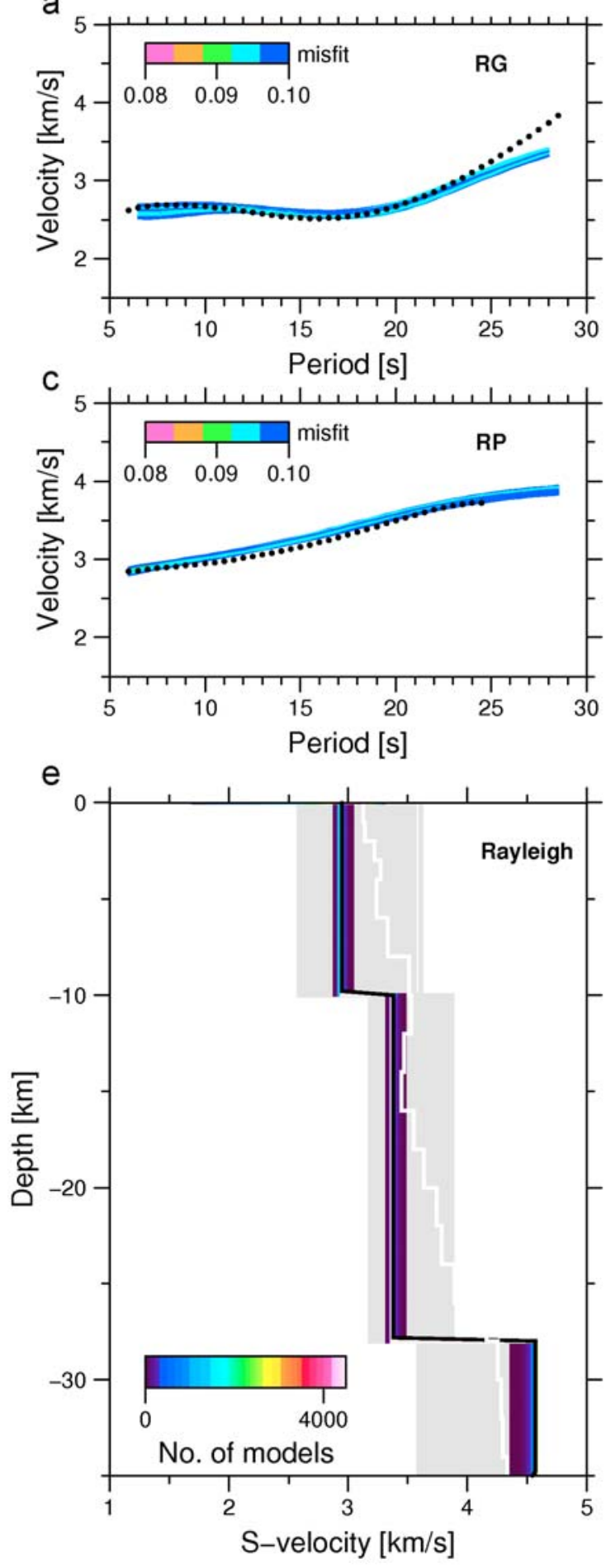

b
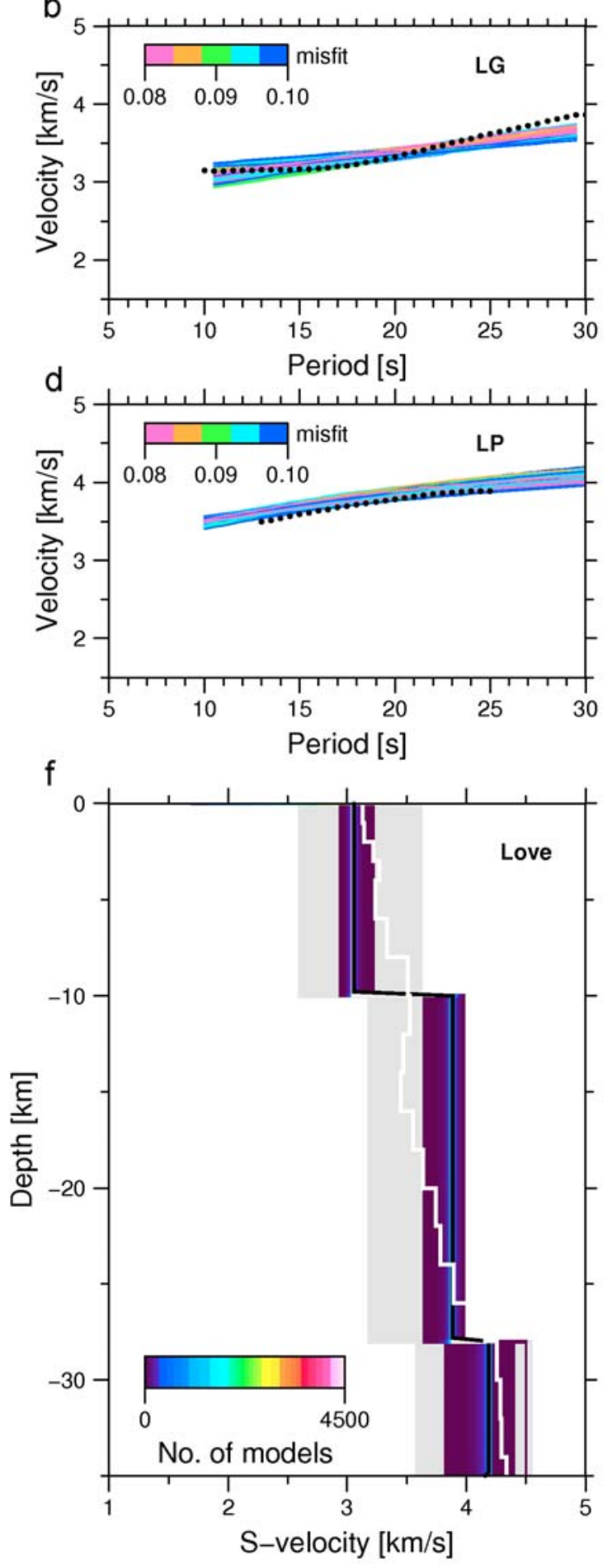

Figure 8. Inversion results for (e) Rayleigh and (f) Love wave group and phase velocity dispersion curves measured between Tikorangi and Matakana using fixed layer thicknesses. The gray areas show the ensemble of all 10,050 models evaluated, and the colors illustrate the density distributions of models with misfit better than 0.1. The white line shows the average model for the results of Horspool et al. [2006]. (a-d) The measured Rayleigh group (RG, Figure 8a) and Rayleigh phase (RP, Figure 8c) dispersion curves (black circles) and Love group (LG, Figure 8b) and Love phase (LP, Figure 8d) dispersion curves (black dots) on top of 100 synthetic dispersion curves that were drawn randomly from the corresponding ensemble of models with misfits smaller than 0.1 . 

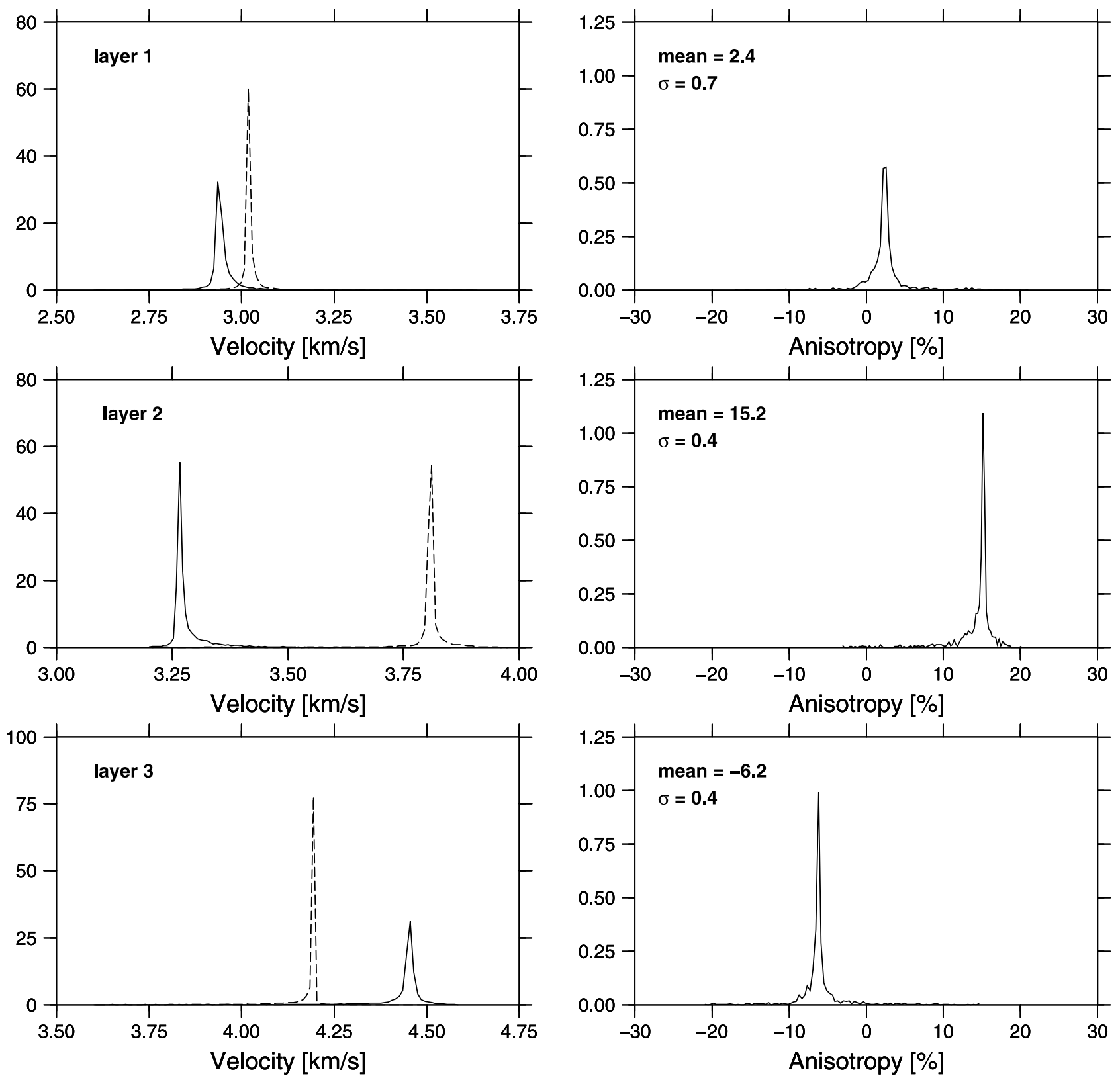

Figure 9. Estimates of radial anisotropy in the upper (layer 1) and lower crust (layer 2) and the uppermost mantle (layer 3). (left) Histograms for S velocity calculated from the Rayleigh wave inversion ensemble (dashed lines) and Love wave inversion ensemble (solid lines) shown in Figure 8. (right) Histograms for radial anisotropy, calculated by randomly drawing 1000 values from Figure 9 (left).

noise correlations show good agreement with the results of earlier studies based on active source experiments and teleseismic earthquakes. In particular, the inversion of Rayleigh wave phase and group velocity dispersion curves yields a Moho depth of $\sim 28 \mathrm{~km}$, in close agreement with the estimates of Stern et al. [1987] and Horspool et al. [2006]. We have extended previous studies of the Northland Peninsula by analyzing horizontal component records, which have allowed us to estimate values for radial anisotropy in the crust of $2-15 \%$ by comparing the shear velocity profiles inferred from Love and Rayleigh wave dispersion curves.
[32] Acknowledgments. We thank Fan-Chi Lin, Laura Brooks, Lionel Carter, Tim Stern, Michael Ritzwoller, Yingjie Yang, Misha Barmin, Charles Ammon, Malcolm Sambridge, and Marc Wathelet for their constructive comments and for making their software available to us. Figures in this publication have been produced with the aid of GMT [Wessel and Smith, 1995] and Matplotlib [Hunter, 2007]. Funding for this work and for the NORD deployment was provided by the Royal Society of New Zealand Marsden Fund. Yannik Behr's work was funded by a ViceChancellor's Strategic Research Scholarship, Victoria University of Wellington, New Zealand.

\section{References}

Audoine, E., M. K. Savage, and K. Gledhill (2004), Anisotropic structure under a back arc spreading region, the Taupo Volcanic Zone, New Zealand, J. Geophys. Res., 109, B11305, doi:10.1029/2003JB002932. 
Balfour, N. J., M. K. Savage, and J. Townend (2005), Stress and crustal anisotropy in Marlborough, New Zealand: Evidence for low fault strength and structure-controlled anisotropy, Geophys. J. Int., 163, 1073-1086, doi:10.1111/j.1365-246X.2005.02783.x.

Bensen, G., M. Ritzwoller, M. Barmin, A. Levshin, F. Lin, M. Moschetti, N. Shapiro, and Y. Yang (2007), Processing seismic ambient noise data to obtain reliable broad-band surface wave dispersion measurements, Geophys. J. Int., 169, 1239-1260, doi:10.1111/j.1365-246X.2007. 03374.x.

Bensen, G. D., M. H. Ritzwoller, and N. M. Shapiro (2008), Broadband ambient noise surface wave tomography across the United States, J. Geophys. Res., 113, B05306, doi:10.1029/2007JB005248.

Brenguier, F., N. M. Shapiro, M. Campillo, A. Nercessian, and V. Ferrazzin (2007), 3-D surface wave tomography of the Piton de la Fournaise volcano using seismic noise correlations, Geophys. Res. Lett., 34, L02305, doi:10.1029/2006GL028586.

Brooks, L. A., J. Townend, P. Gerstoft, S. Bannister, and L. Carter (2009a), Fundamental and higher-mode Rayleigh wave characteristics of ambien seismic noise in New Zealand, Geophys. Res. Lett., 36, L23303, doi:10.1029/2009GL040434.

Brooks, L. A., J. Townend, P. Gerstoft, S. Bannister, and L. Carter (2009b), Characterising the New Zealand ambient seismic noise field: An oceanographic interpretation of western North Island spectra and beamforming results, in Acoustics 2009: Research to Consulting: Proceedings of the Annual Conference of the Australian Acoustical Society, edited by A. C. Zander and C. Q. Howard, paper 12, Sch. of Mech. Eng., Adelaide, South Australia, Australia.

Derode, A., E. Larose, M. Tanter, J. de Rosny, A. Tourin, M. Campillo, and M. Fink (2003), Recovering the Green's function from field-field correlations in an open scattering medium, J. Acoust. Soc. Am., 113, 2973-2976, doi:10.1121/1.1570436.

Duclos, M. (2005), Insights on plate boundary deformation from seismic anisotropy in the New Zealand upper mantle, Ph.D. thesis, Victoria Univ. of Wellington, Wellington, New Zealand.

Dunkin, J. W. (1965), Computation of modal solutions in layered, elastic media at high frequencies, Bull. Seismol. Soc. Am., 55, 335-358.

Endrun, B., T. Meier, S. Lebedev, M. Bohnhoff, G. Stavrakakis, and H.-P. Harjes (2008), S velocity structure and radial anisotropy in the Aegean region from surface wave dispersion, Geophys. J. Int., 174, 593-616, doi:10.1111/j.1365-246X.2008.03802.x.

Fowler, C. M. R. (2005), The Solid Earth, Cambridge Univ. Press, Cambridge, U. K.

Funnell, R., D. Chapman, R. Allis, and P. Armstrong (1996), Thermal state of the Taranaki Basin, New Zealand, J. Geophys. Res., 101(B11), 25,197-25,215, doi:10.1029/96JB01341.

Gerst, A., and M. K. Savage (2004), Seismic anisotropy beneath Ruapehu volcano: A possible eruption forecasting tool, Science, 306, 1543-1547, doi: $10.1126 /$ science. 1103445

Gorman, R. M., K. R. Bryan, and A. K. Laing (2003), Wave hindcast for the New Zealand region: Nearshore validation and coastal wave climate, N. Z. J. Mar. Freshw. Res., 37(3), 567-588.

Goutorbe, B., F. Lucazeau, and A. Bonneville (2008), Surface heat flow and the mantle contribution on the margins of Australia, Geochem. Geophys. Geosyst., 9, Q05011, doi:10.1029/2007GC001924.

Heming, R. F. (1980), Patterns of Quaternary basaltic volcanism in northern North Island, New Zealand, N. Z. J. Geol. Geophys., 23, 335-344.

Herzer, R. H. (1995), Seismic stratigraphy of a buried volcanic arc, Northland, New Zealand and implications for Neogene subduction, Mar. Pet. Geol., 12, 511-531, doi:10.1016/0264-8172(95)91506-K.

Hoke, L., and R. Sutherland (1999), Mantle melting beneath New Zealand revealed by helium in gas discharges, technical report, GNS Sci., Lower Hutt, New Zealand.

Holt, W. E., and T. A. Stern (1994), Subduction, platform subsidence, and foreland thrust loading: The late Tertiary development of Taranaki Basin, New Zealand, Tectonics, 13, 1068-1092, doi:10.1029/94TC00454.

Horspool, N. A., M. K. Savage, and S. Bannister (2006), Implications for intraplate volcanism and back-arc deformation in northwestern New Zealand, from joint inversion of receiver functions and surface waves, Geophys. J. Int., 166, 1466-1483, doi:10.1111/j.1365-246X.2006. 03016.X.

Huang, Y., C. Hawkesworth, P. van Calsteren, I. Smith, and P. Black (1997), Melt generation models for the Auckland volcanic field, New Zealand: Constraints from U-Th isotopes, Earth Planet. Sci. Lett., 149, 67-84, doi:10.1016/S0012-821X(97)00064-2.

Hunter, J. D. (2007), Matplotlib: A 2D graphics environment, Comput. Sci. Eng., 9(3), 90-95, doi:10.1109/MCSE.2007.55

Isaac, M. J., R. H. Herzer, F. J. Brook, and B. W. Hayward (1994), Cretaceous and Cenozoic Sedimentary Basins of Northland, New Zealand, Monogr. 8, Inst. of Geol. and Nucl. Sci., Lower Hutt, New Zealand.
Juliá, J., C. J. Ammon, R. B. Herrmann, and A. M. Correig (2000), Joint inversion of receiver function and surface wave dispersion observations, Geophys. J. Int., 143, 99-112, doi:10.1046/j.1365-246x.2000.00217.x.

Laing, A. K. (2000), New Zealand wave climate from satellite observations, N. Z. J. Mar. Freshw. Res., 34, 727-744.

Larose, E., L. Margerin, A. Derode, B. van Tiggelen, M. Campillo, N. Shapiro, A. Paul, L. Stehly, and M. Tanter (2006), Correlation of random wavefields: An interdisciplinary review, Geophysics, 71, SI11-SI21, doi:10.1190/1.2213356

Levshin, A., L. Ratnikova, and J. Berger (1992), Peculiarities of surfacewave propagation across central Europe, Bull. Seismol. Soc. Am., 82, 2464-2493.

Liang, C., and C. A. Langston (2009), Three-dimensional crustal structure of eastern North America extracted from ambient noise, J. Geophys. Res. 114, B03310, doi:10.1029/2008JB005919.

Lin, F.-C., M. H. Ritzwoller, J. Townend, S. Bannister, and M. K. Savage (2007), Ambient noise Rayleigh wave tomography of New Zealand Geophys. J. Int., 170, 649-666, doi:10.1111/j.1365-246X.2007.03414.x.

Lin, F.-C., M. P. Moschetti, and M. H. Ritzwoller (2008), Surface wave tomography of the western United States from ambient seismic noise: Rayleigh and Love wave phase velocity maps, Geophys. J. Int., 173, 281-298, doi:10.1111/j.1365-246X.2008.03720.x.

Longuet-Higgins, M. S. (1950), A theory of the origin of microseisms, Philos. Trans. R. Soc. London, 243, 1-35, doi:10.1098/rsta.1950.0012.

Marson-Pidgeon, K., M. K. Savage, K. Gledhill, and G. Stuart (1999), Seismic anisotropy beneath the lower half of the North Island, New Zealand, J. Geophys. Res., 104, 20,277-20,286, doi:10.1029/1999JB900212.

Mortimer, N. (2004), New Zealand's Geological Foundations, Gondwana Res., 7(1), 261-272, doi:10.1016/S1342-937X(05)70324-5.

Moschetti, M. P., M. H. Ritzwoller, F. Lin and Y. Yang (2010), Seismic evidence for widespread western US deep-crustal deformation caused by extension, Nature, 464, 885-889, doi:10.1038/nature08951.

Nishida, K., H. Kawakatsu, and K. Obara (2008), Three-dimensional crustal $\mathrm{S}$ wave velocity structure in Japan using microseismic data recorded by Hi-net tiltmeters, J. Geophys. Res., 113, B10302, doi:10.1029/2007JB005395.

Pandey, O. P. (1981), Terrestrial heat flow in New Zealand, Ph.D. thesis, Victoria Univ. of Wellington, Wellington, New Zealand.

Parker, R. L. (1994), Geophysical Inverse Theory, Princeton Univ. Press, Princeton, N. J.

Paul, A., M. Campillo, L. Margerin, E. Larose, and A. Derode (2005), Empirical synthesis of time-asymmetrical Green functions from the correlation of coda waves, J. Geophys. Res., 110, B08302, doi:10.1029/ 2004JB003521.

Pickrill, R., and J. Mitchell (1979), Ocean wave characteristics around New Zealand, N. Z. J. Mar. Freshw. Res., 13, 501-520.

Sambridge, M. (1999), Geophysical inversion with the neighbourhood algorithm -I. searching a parameter space, Geophys. J. Int., 138 , 479-494, doi:10.1046/j.1365-246X.1999.00876.x.

Sánchez-Sesma, F. J., and M. Campillo (2006), Retrieval of the Green function from cross-correlation: The canonical elastic problem, Bull. Seismol. Soc. Am., 96, 1182-1191, doi:10.1785/0120050181.

Savage, M. K. (1998), Lower crustal anisotropy or dipping boundaries? Effects on receiver functions and a case study in New Zealand, J. Geophys. Res., 103, 15,069-15,087, doi:10.1029/98JB00795.

Savage, M. K., J. Park, and H. Todd (2007), Velocity and anisotropy structure at the Hikurangi subduction margin, New Zealand from receive functions, Geophys. J. Int., 168, 1034-1050, doi:10.1111/j.1365-246X. 2006.03086.x.

Seward, A. M., C. M. Henderson, and E. G. C. Smith (2009), Models of the upper mantle beneath the central North Island, New Zealand, from speeds and anisotropy of subhorizontal P waves (Pn), J. Geophys. Res., 114 B01301, doi:10.1029/2008JB005805.

Shapiro, N. M., and M. Campillo (2004), Emergence of broadband Rayleigh waves from correlations of the ambient seismic noise, Geophys. Res. Lett., 31, L07614, doi:10.1029/2004GL019491.

Shapiro, N. M., M. H. Ritzwoller, P. Molnar, and V. Levin (2004), Thinning and flow of Tibetan crust constrained by seismic anisotropy, Science, 305, 233-236, doi:10.1126/science.1098276.

Shapiro, N. M., M. Campillo, L. Stehly, and M. H. Ritzwoller (2005), High-resolution surface-wave tomography from ambient seismic noise, Science, 307, 1615-1618, doi:10.1126/science.1108339.

Sinclair, M. R. (2002), Extratropical transition of southwest Pacific tropical cyclones. Part I: Climatology and mean structure changes, Mon. Weather Rev., 130, 590-609, doi:10.1175/1520-0493(2002)130<0590:ETOSPT > 2.0.CO;2

Smith, I. E. M., T. Okada, T. Itaya, and P. M. Black (1993), Age relationships and tectonic implications of late Cenozoic basaltic volcanism in Northland, New Zealand, N. Z. J. Geol. Geophys., 36, 385-393. 
Snieder, R. (2004), Extracting the Green's function from the correlation of coda waves: A derivation based on stationary phase, Phys. Rev., 69 046610, doi:10.1103/PhysRevE.69.046610.

Snoke, J. A., and M. Sambridge (2002), Constraints on the S wave velocity structure in a continental shield from surface wave data: Comparing linearized least squares inversion and the direct search Neighbourhood Algorithm, J. Geophys. Res., 107(B5), 2094, doi:10.1029/ 2001JB000498

Spörli, K. B. (1989), Geology of Northland: Accretion, allochthons and arcs at the edge of the New Zealand micro-continent, in Tectonic Framework of Northland, pp. 3-14, R. Soc. of N. Z., Wellington.

Stein, S., and M. Wysession (2003), An Introduction to Seismology, Earthquakes, and Earth Structure, Blackwell, Malden, Mass.

Stern, T. A., E. G. C. Smith, F. J. Davey, and K. J. Muirhead (1987), Crustal and upper mantle structure of the northwestern North Island, New Zealand, from seismic refraction data, Geophys. J. R. Astron. Soc., 91, 913-936, doi:10.1111/j.1365-246X.1987.tb01674.x.

Stern, T. A., W. R. Stratford, and M. L. Salmon (2006), Subduction evolution and mantle dynamics at a continental margin: Central North Island, New Zealand, Rev. Geophys., 44, RG4002, doi:10.1029/2005RG000171.

Stratford, W. R., and T. A. Stern (2006), Crust and upper mantle structure of a continental backarc: Central North Island, New Zealand, Geophys. J. Int., 166, 469-484, doi:10.1111/j.1365-246X.2006.02967.x.

Sutherland, R. (1999), Basement geology and tectonic development of the greater New Zealand region: An interpretation from regional magnetic data, Tectonophysics, 308, 341-362, doi:10.1016/S0040-1951(99) 00108-0.

Townend, J. (1999), Heat flow through the West Coast, South Island, New Zealand, N. Z. J. Geol. Geophys., 42, 21-31.

Tsai, V. C. (2009), On establishing the accuracy of noise tomography travel-time measurements in a realistic medium, Geophys. J. Int., 178 , 1555-1564, doi:10.1111/j.1365-246X.2009.04239.x.

Wapenaar, K. (2006), Green's function retrieval by cross-correlation in case of one-sided illumination, Geophys. Res. Lett., 33, L19304, doi:10.1029/2006GL027747.

Wathelet, M. (2005), Array recordings of ambient vibrations: Surface wave inversion, Ph.D. thesis, Fac. des Sci. Appl., Univ. of Liége, Liége, Belgium.

Wathelet, M., D. Jongmans, and M. Ohrnberger (2004), Surface-wave inversion using a direct search algorithm and its application to ambient vibration measurements, Near Surf. Geophys., 2, 211-221.
Weaver, R., and O. Lobkis (2001a), On the emergence of the Green's function in the correlations of a diffuse field, J. Acoust. Soc. Am., 40, 435-439.

Weaver, R. L., and O. I. Lobkis (2001b), Ultrasonics without a source: Thermal fluctuation correlations at $\mathrm{MHz}$ frequencies, Phys. Rev. Lett., 87, doi:10.1103/PhysRevLett.87.134301.

Weaver, R. L., and O. I. Lobkis (2004), Diffuse fields in open systems and the emergence of the Green's function, J. Acoust. Soc. Am., 116, 2731-2734, doi:10.1121/1.1810232.

Weaver, R. L., and O. I. Lobkis (2005), Fluctuations in diffuse field-field correlations and the emergence of the green's function in open systems, J. Acoust. Soc. Am., 117, 3432-3439, doi:10.1121/1.1898683.

Wessel, P., and W. H. F. Smith (1995), New version of the Generic Mapping Tools released, Eos Trans. AGU, 76, 329, doi:10.1029/95EO00198.

Yang, Y., M. H. Ritzwoller, A. Levshin, and N. Shapiro (2007), Ambient noise Rayleigh wave tomography across Europe, Geophys. J. Int., 168, 259-274, doi:10.1111/j.1365-246X.2006.03203.X.

Yao, H., and R. van der Hilst (2009), Analysis of ambient noise energy distribution and phase velocity bias in ambient noise tomography, with application to SE Tibet, Geophys. J. Int., 179, 1113-1132, doi:10.1111/ j.1365-246X.2009.04329.x.

Yao, H., R. D. van der Hilst, and M. V. de Hoop (2006), Surface-wave array tomography in SE Tibet from ambient seismic noise and twostation analysis - I. Phase velocity maps, Geophys. J. Int., 166 , 732-744, doi:10.1111/j.1365-246X.2006.03028.x.

Yao, H., C. Beghein, and R. D. van der Hilst (2008), Surface wave array tomography in SE Tibet from ambient seismic noise and two-station analysis - II. Crustal and upper-mantle structure, Geophys. J. Int., 173, doi:10.1111/j.1365-246X.2007.03696.x.

S. Bannister, GNS Science, 1, Fairway Dr., Avalon, PO Box 30368, Lower Hutt 5010, New Zealand. (s.Bannister@gns.cri.nz)

Y. Behr, M. K. Savage, and J. Townend, School of Geography, Environment and Earth Sciences, Victoria University of Wellington, PO Box 600, Wellington, New Zealand. (yannik.behr@vuw.ac.nz; martha. savage@vuw.ac.nz; john.townend@vuw.ac.nz) 